\title{
Monitoramento de barragens utilizando sísmica passiva - um estudo a partir de modelos sintéticos
}

\author{
Guilherme Zakarewicz de Aguiar¹, Susanne Tainá Ramalho Maciel1', Victor José Cavalcanti Bezerra Guedes', Welitom
}

Rodrigues Borges ${ }^{1}$, Luciano Soares da Cunha' ${ }^{1}$ Universidade de Brasília (UnB)

Copyright 2021, SBGf - Sociedade Brasileira de Geofísica

This paper was prepared for presentation during the $17^{\text {th }}$ International Congress of the Brazilian Geophysical Society held in Rio de Janeiro, Brazil, 16-19 August 2021.

Contents of this paper were reviewed by the Technical Committee of the $17^{\text {th }}$ International Congress of the Brazilian Geophysical Society and do not necessarily represent any position of the SBGf, its officers or members. Electronic reproduction or represent any position of the SBGf, its officers or members. Electronic reproduction or
storage of any part of this paper for commercial purposes without the written consent storage of any part of this paper for commercial pur
of the Brazilian Geophysical Society is prohibited.

\begin{abstract}
Internal erosion caused by infiltration and piping is the main cause of earthen dams' failures. Traditional methods of inspection are not representative and are unable to cover the entire structure. The seismic interferometry emerges as an alternative for the continuous monitoring of earthen dams from the detection of variations in seismic velocities caused by layers saturation. The objective of this study is to evaluate the use of seismic interferometry for monitoring the Paranoá dam (Brasília, DF). We generated synthetic models that simulate a passive acquisition at the dam. To obtain a geological model that represents the expected structure, we performed an acquisition with active sources in the region and applied inversion techniques to retrieve the seismic velocities. We simulated acquisitions in a simple geological model of two horizontal layers for better understand the behavior of seismograms recovered through interferometry. We simulated a layer's saturation by varying the velocities and noticed that the method was able to detect such variations. The method also verified changes in a most complex geological model. In addition, we implemented a technique to monitor velocities variations using the semblance calculation approach. We recommend a wide coverage of receivers and the use of techniques such as monitoring panels in order to detect temporal variations in seismic velocities.
\end{abstract}

\section{Introdução}

Barragens e diques são estruturas construídas por diferentes materiais e possuem diversas finalidades. Existe uma necessidade de monitorar continuamente essas estruturas devido às graves consequências causadas por rompimentos, o que traz prejuízos para o meio ambiente e pode resultar em perdas de vidas. A principal causa do falhamento de barragens de terra é a erosão interna causada pela água (Flores-Berrones et al., 2011). Os principais fenômenos que provocam a erosão são a surgência, o piping e a saturação do meio. Métodos tradicionais de inspeção são incapazes de cobrir toda a área de interesse e não detectam sinais iniciais da erosão interna (Albuquerque et al., 2019), e vários métodos geofísicos já são utilizados para suplementar essas inspeções, como a eletrorresistividade, radar de penetração no solo e sísmica.

A presença de ruído nos sismogramas é em geral descartada, para realçar os sinais provenientes de terremotos, ou outros sinais de interesse mais comuns. No entanto, atualmente crescem as aplicações do estudo de partes do sinal que usualmente são tratadas como ruído. Por exemplo, o processamento de múltiplas amplia a iluminação da subsuperfície (Berkhout, 2017), e as difrações podem ser utilizadas para imagear estruturas abaixo do limite de resolução (Maciel e Biloti, 2020).

A interferometria sísmica é uma técnica capaz de recuperar a função de Green entre dois receptores registrando ruído ambiental (Wapenaar et al., 2010). Autores já estudam a aplicação do método para o monitoramento de barragens, como feito por Planès et al. (2016) e de Wit e Olivier (2018). Ambos os trabalhos foram capazes de detectar mudanças de velocidade na ordem de $0.1 \%$ e sugerem o uso da técnica como forma não invasiva para monitorar essas estruturas e previnir acidentes provocados por infiltrações e rupturas.

O escopo deste trabalho é a investigação geofísica da estrutura da barrage do Paranoá, em Brasília (DF). Para isso, calculamos os perfis de $V p$ e $V s$ na barrage a partir da realização de uma aquisição com fontes ativas e aplicação de dois métodos de inversão, a Tomografia de Refração Sísmica e o MASW (Multichannel analysis of surface waves). Avaliamos também a possibilidade do uso da interferometria sísmica para o monitoramento contínuo da barragem usando dados de sísmica passiva. Para isso, criamos modelos sintéticos de aquisição de sísmica passiva cujos modelos de velocidades são baseados nas inversões obtidas nan ossa investigação inicial, e implementamos uma técnica nova de monitoramento, baseada em painéis de monitoramento.

\section{Materiais e Métodos}

\section{Processamento e Inversão dos Dados Sísmicos Ativos}

Realizamos uma aquisição com fontes ativas no pé da barragem do Paranoá (Figura 1). A linha possui um total de 475 metros, em que os receptors foram espaçados 5 metros, e os receptores, 10 metros. Para obter um perfil de velocidade da onda $P$, aplicamos a tomografia de refração sísmica por meio da inversão Time-terms. Para isso, utilizamos o programa PickWin para edição dos traços e marcação das primeiras chegadas e o programa PlotRefra para efetuar a inversão. Para obter um modelo de Vs, aplicamos o MASW (Multichannel Analysis of Surface Waves), através do programa Seis/mager. 


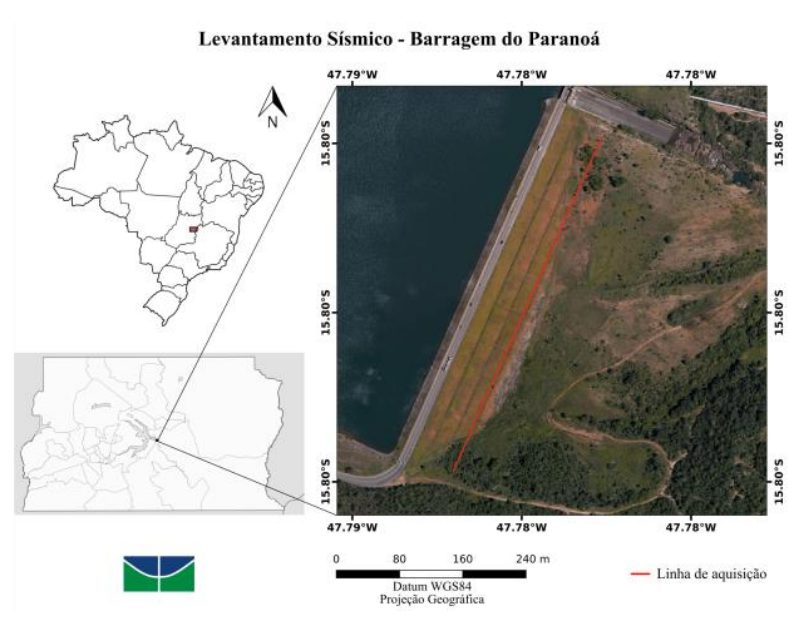

Figura 1 - localização da linha de aquisição sísmica.

\section{Inteferometria Sísmica}

As chegadas difusas em sinais sísmicos, referidas como caudas dos sismogramas, começaram a ser aplicadas para reconstruir refletores com o trabalho de Campillo e Paul (2003). É possível recuperar refletores em subsuperfície através da correlação cruzada entre os registros ruidosos (Draganov et al., 2009). Para exemplificar a teoria, consideramos uma situação unidimensional como feito por Wapenaar et al. (2010). A Figura 2 mostra uma onda plana em $x=x s$ e $t=t 0$, se propagando ao longo do eixo $x$. Assumimos que a velocidade do meio é constante, c, e o meio não apresenta perdas. O registro pelo receptor xa é dado por $\mathrm{G}(\mathrm{xa}, \mathrm{xs}, \mathrm{t})$, em que $\mathrm{G}$ representa a função de Green. Assim, a resposta é um impulso em ta $=(\mathrm{xa}-\mathrm{xs}) / \mathrm{c}$ (Figura $2 b)$, de forma que $G(x a, x s, t)=\delta(t-t a)$, em que $\delta$ é a distribuição chamada Delta de Dirac. $O$ mesmo vale para $\mathrm{xb}: \mathrm{G}(\mathrm{xb}, \mathrm{xs}, \mathrm{t})=\delta(\mathrm{t}-\mathrm{tb})$ (Figura $2 \mathrm{c})$. A interferometria sísmica consiste na correlação cruzada entre as respostas dos receptores. Como o caminho da onda emitida por xs possui os pontos xa e xb em comum, o tempo de trânsito entre xa e xb é cancelado no processo da correlação cruzada e resulta no tempo de percurso entre as estações, ou seja, tb - ta $=(x b-x a) / c$. Dessa forma, a Figura 2d mostra o registro de um impulso em $\mathrm{xb}$ caso a fonte estivesse em xa.

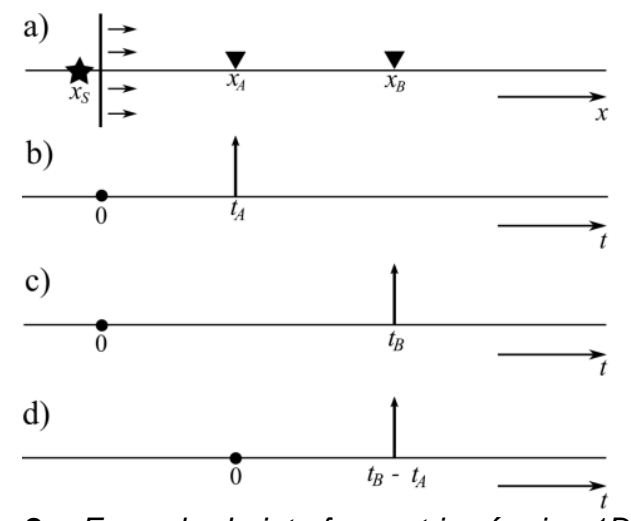

Figura 2 - Exemplo da interferometria sísmica 1D. (a) $A$ fonte em xs emite uma onda plana. (b) Resposta observada pelo receptor xa e (c) observada por xb. (d)
Correlação cruzada entre as respostas de xa e xb, correspondente caso caso o segundo receptor registrasse um impulse enviado a partir do primeiro. Modificado de Wapenaar et al. (2010).

\section{Dados Sintéticos Passivos}

A interferometria sísmica possui uma série de condições. O campo de ondas deve ser difuso e as fontes não podem ser correlacionadas. Além disso, a teoria não prevê fatores como a atenuação e espalhamento geométrico das ondas. Neste sentido, há uma necessidade de desenvolver modelos sintéticos robustos para testar aplicações e validar resultados obtidos experimentalmente. Para gerar os modelos utilizados neste trabalho, utilizamos o modelador de diferenças finitas fdelmodc desenvolvido por Thorbecke e Draganov (2011). Além de simular aquisições passivas de longa duração através da modelagem de fontes ruidosas espalhadas em subsuperfície, o programa possui código aberto e pode ser utilizado pela comunidade científica para estudar as diferentes aplicações da interferometria sísmica.

Para melhor compreender o funcionamento do método, inicialmente geramos modelos simples, de duas camadas horizontais (Figura 3), e variamos parâmetros como o tempo total de gravação e o espaçamento de receptores. Além disso, também simulamos um processo de saturação da primeira camada e realizamos uma gravação continua (time-lapse).

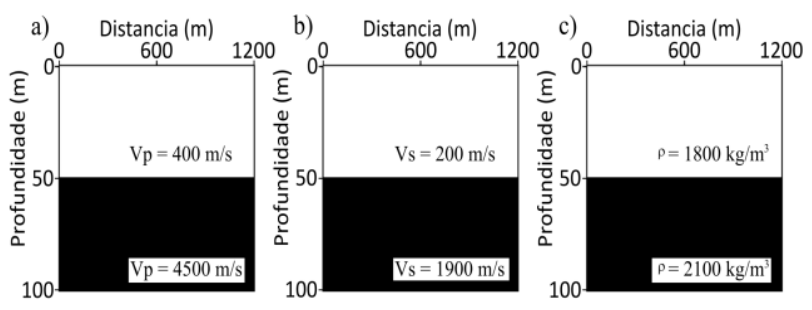

Figura 3 - Propriedades físicas dos modelos de duas camadas horizontais. (a) Velocidade da onda $P$ e (b) da onda $S(\mathrm{~m} / \mathrm{s})$; (c) Densidade $\left(\mathrm{kg} / \mathrm{m}^{3}\right)$.

As bordas do modelo foram definidas como absorventes; assim, a segunda camada estende-se infinitamente em profundidade, mas foi limitada a 50 metros de espessura no modelo. A wavelet da fonte é definida como a Ricker.

Com base nos resultados obtidos após a aquisição sísmica com fontes ativas na barragem, elaboramos um modelo geológico de maior complexidade para representar a estrutura da barragem. A frequência máxima dos receptores foi de $30 \mathrm{~Hz}$, a amostragem (dt) é de 0.009 segundos e a discretização do modelo ( $d x$ e dz) é 1 metro.

\section{Painéis de Monitoramento}

Propomos o monitoramento de barragens através de sequências de painéis de coerência, semelhante aos utilizados na análise de velocidades, aqui denominadas de painéis de monitoramento. Desenvolvemos os painéis para observar se existe algum tipo de alteração na velocidade do meio ou na profundidade dos refletores. Implementamos códigos por meio da linguagem Python 
para calcular o tempo de trânsito das ondas. Para um conjunto de valores de profundidade e velocidade, o código calcula a Semblance, conforme apresentado por Neidell e Taner (1971), para o sismograma recuperado pela interferometria. Os valores de coerência são sintetizados em um painel cujo eixo $x$ representa a velocidade, e eixo y, a espessura da camada. Espera-se que a mancha gerada possua valores mais altos em torno da velocidade e profundidade determinadas para cada modelo. Geramos painéis de monitoramento para os arquivos obtidos após a gravação contínua para verificar se são sensíveis a variações de velocidades. Até - momento da conclusão do trabalho final, implementamos os painéis de monitoramento para meios homogêneos e refletores planos. Nossos próximos passos da pesquisa incluem a implementação do método para meios mais complexos.

\section{Resultados}

\section{Dados Sísmicos Ativos}

Após as inversões por Tomografia Sísmica de Refração e MASW, geramos perfis bidimensionais de velocidades $\mathrm{Vp}$ e Vs, apresentados nas Figuras 4a e 4b. É possível observar em ambos os modelos uma camada inicial de baixa velocidade (Vp entre 200 e $500 \mathrm{~m} / \mathrm{s}$ e Vs entre 100 e $350 \mathrm{~m} / \mathrm{s}$ ), marcada pela cor azul-escuro, entre 0 e 10 metros de profundidade. Interpretamos como solo inconsolidado. Depois, há uma zona de maior velocidade, marcada pela cor verde-claro (Vp entre 800 e $2200 \mathrm{~m} / \mathrm{s}$ e Vs entre 600 e $850 \mathrm{~m} / \mathrm{s}$ ), interpretada como uma região composta por material argiloso compactado do aterro da barragem.$$
\text { a) }
$$

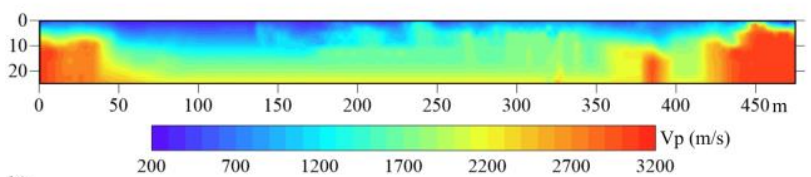

b)

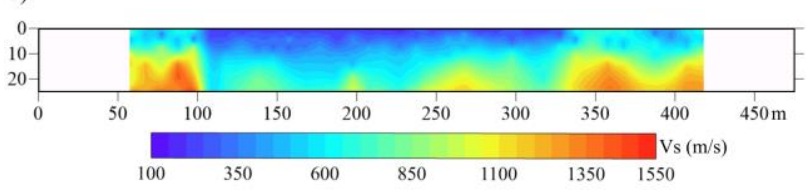

Figura 4-Modelos de velocidade (a) Vp e (b) Vs da barragem do Paranoá.

Notamos o início de uma terceira camada, marcada pela cor amarela (Vp entre 2200 e 2500 m/s e Vs entre 900 e $1100 \mathrm{~m} / \mathrm{s}$ ), próxima ao limite de profundidade dos modelos. Além disso, é possível observar estruturas de maior velocidade nas bordas do perfil de $\mathrm{Vp}$, acima de $2500 \mathrm{~m} / \mathrm{s}$. Tais feições podem representar as ombreiras da barragem (maciço rochoso), mas não incluímos essa velocidade nos modelos sintéticos por não termos maiores evidências de que representam o maciço rochoso.

\section{Dados Sintéticos Passivos}

O número de fontes ruidosas foi fixado como 100 em todas as modelagens deste estudo. A Figura 5 apresenta um exemplo da aleatoriedade das fontes, em que cada traço preto representa uma fonte de ruído.

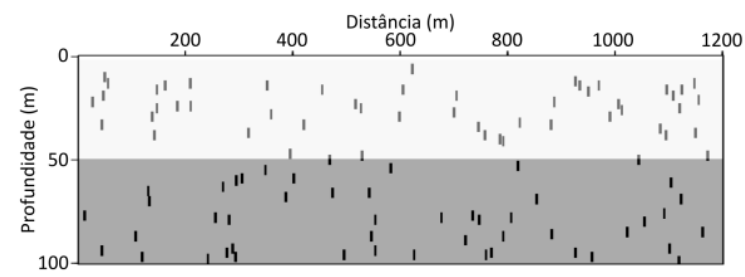

Figura 5 - Fontes ruidosas (traços pretos) distribuídas de forma aleatória ao longo do modelo geológico.

A Figura 6 apresenta os traços emitidos por cada fonte para um tempo de gravação de 6 segundos. É possível notar que as fontes vão sendo ativadas ao longo da aquisição de forma aleatória.

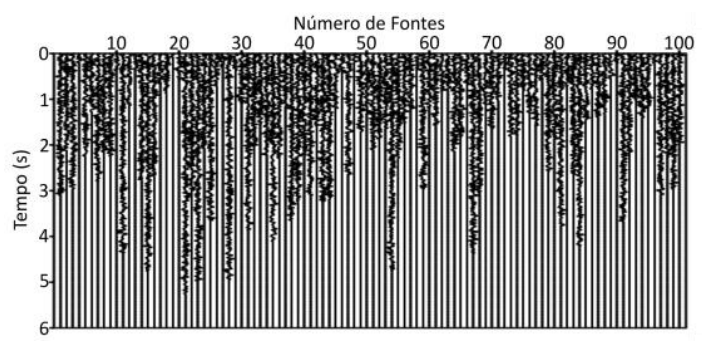

Figura 6 - Traço emitido por cada fonte ao longo do tempo de gravação. As fontes diferem em amplitude e frequência.

A primeira análise foi feita a partir da variação do tempo de gravação. Simulamos uma fonte ativa no meio da superfície do modelo (Figura 7a) para servir de comparação com os sismogramas recuperados pela interferometria. Os valores de tempo de gravação utilizados na modelagem foram 6, 12, 30, 60 e 120 segundos. Os resultados são apresentados na Figura 7.

A maior quantidade de dados melhora a qualidade das correlações entre os traços, o que diminui a amplitude do ruído presente nos modelos. A resolução da hipérbole de reflexão melhora ao longo dos sismogramas, o que indica que mais tempo de gravação em campo resulta em sismogramas com as feições mais destacadas e com menos ruído ambiental. 

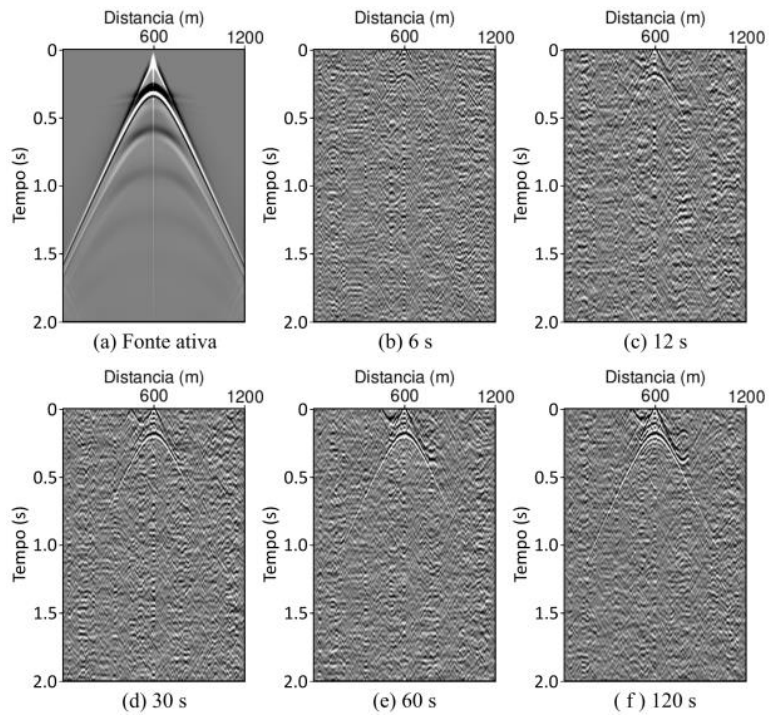

Figura 7 - Sismogramas recuperados após a interferometria sísmica com variação no tempo de gravação.

Também variamos a distância entre os receptores, ou seja, a quantidade total de geofones usados na aquisição. O tempo de gravação foi mantido fixo em 30 segundos, e os resultados são apresentados na Figura 8. Até o caso em que a distância é de 8 metros (Figura $8 \mathrm{e}$ ), as imagens não apresentam alterações perceptíveis na resolução da hipérbole ou na amplitude do ruído. Contudo, ao analisar o resultado gerado pela distância de 20 metros (Figura 8f), notamos uma piora na resolução da hipérbole. Ainda é possível identificar o topo da reflexão, porém o restante do dado é facilmente confundido com ruído. Assim, é preciso cautela na determinação do offset em aquisições para garantir a detecção de todos os alvos de interesse.

Para simular um processo de saturação da camada superficial, alteramos as propriedades físicas de maneira gradativa e realizamos uma gravação contínua, totalizando 330 segundos. De acordo com Knight e Nolen-Hoeksema (1990), a saturação do solo contribui para o aumento de Vp e diminuição de Vs. Dessa maneira, os valores iniciais de Vp e Vs, 400 e 200 m/s respectivamente, foram mudando gradativamente até os valores de 600 e $100 \mathrm{~m} / \mathrm{s}$. As propriedades da camada subjacente permaneceram constantes, conforme apresentado nas análises anteriores.

Dividimos os dados em arquivos de 30 segundos para rodar as correlações e gerar os sismogramas recuperados pela interferometria sísmica. Os resultados são apresentados na Figura 9. É possível notar a alteração na inclinação das assíntotas da hipérbole conforme a Vp aumenta, i.e., o ângulo das assíntotas aumenta em relação à normal. Além disso, também notamos a diminuição do tempo da primeira chegada, i.e, a aproximação do topo da hipérbole à superfície. O imageamento foi capaz de detectar as mudanças causadas pela simulação de um processo de saturação da primeira camada do modelo.
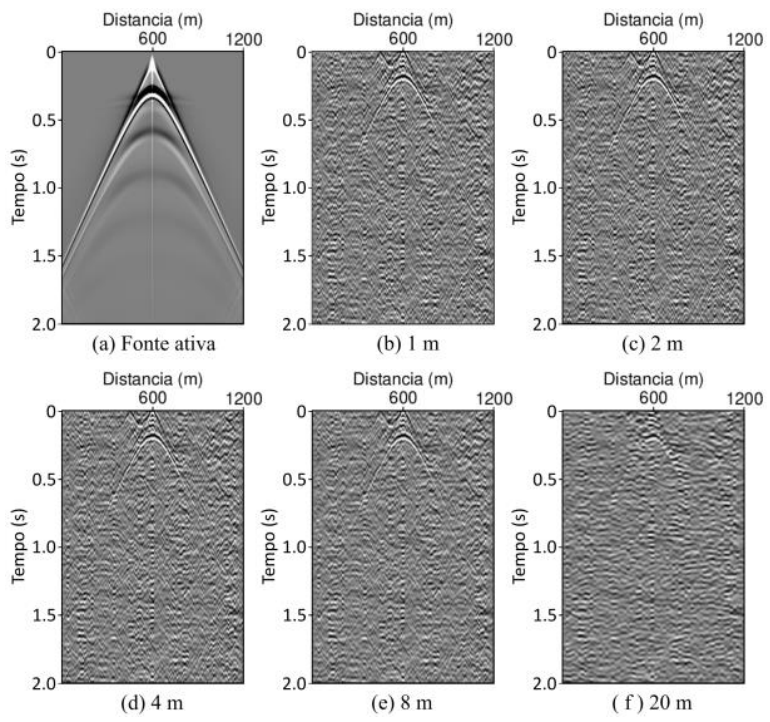

Figura 8 - Sismogramas recuperados após a interferometria sísmica com variação na distância entre os receptores.
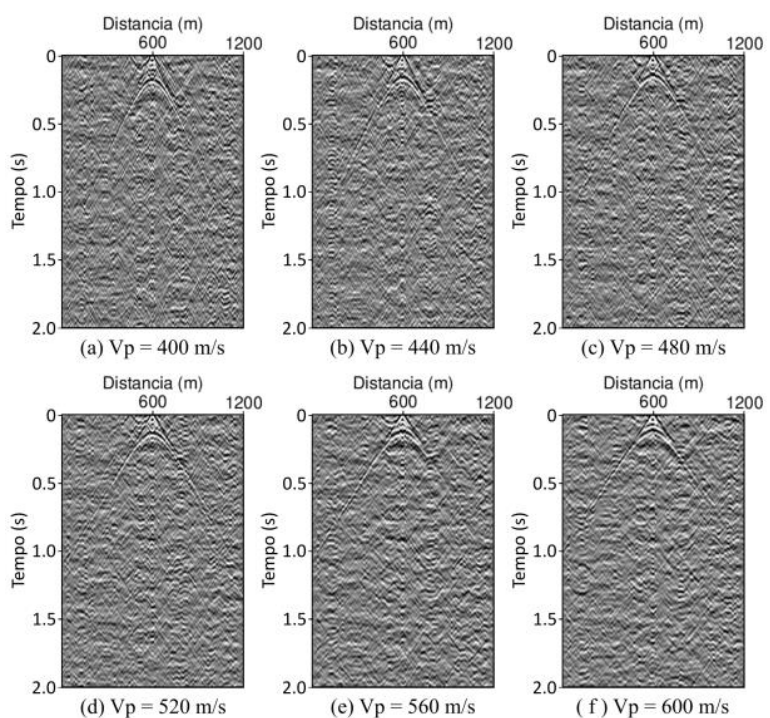

Figura 9 - Sismogramas recuperados após a interferometria sísmica durante o processo de saturação da primeira camada.

Os painéis de monitoramento foram aplicados para verificar alterações na profundidade do refletor e na velocidade da camada para os dados da gravação contínua. A partir das amplitudes obtidas ao longo da curva do tempo de trânsito da onda, calculamos o valor de Semblance. Os resultados são apresentados na Figura 10, em que a cor preta indica menor coerência, e a cor branca, maior.

Percebemos que os valores de profundidade e velocidade que geram maiores coerências são menores que os parâmetros definidos para cada modelo. Os modelos geológicos possuem um refletor horizontal em 50 metros e velocidades que se iniciam em $400 \mathrm{~m} / \mathrm{s}$. Ao analisar o painel gerado para o primeiro modelo (Figura 10a), notamos que as maiores coerências foram 
indicadas para a espessura de 45 metros e velocidade de $375 \mathrm{~m} / \mathrm{s}$.
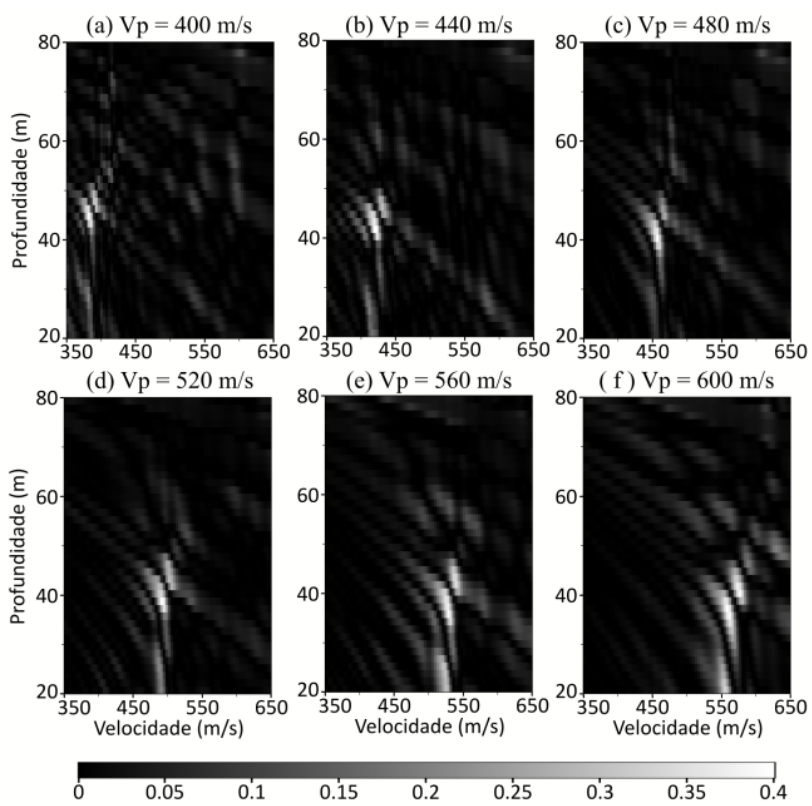

0.05

0.15

Velocidade $(\mathrm{m} / \mathrm{s})$

Figura 10 - Painéis de monitoramento resultantes para os arquivos gerados após a gravação contínua.

A mancha se desloca ao longo do eixo $x$ nos painéis, o que indica um aumento de velocidade da primeira camada. O método proposto é capaz de detectar variações de velocidade. Destacamos que estes resultados são baseados na nossa implementação preliminar, que não inclui a aplicação de atributos básicos para o bom cálculo de coerência, como janela de amplitude, abertura máxima e traçador de raios.

\section{Modelo da Barragem do Paranoá}

A partir das velocidades obtidas pelos modelos (Figura 4), elaboramos um modelo geológico de três camadas para simular aquisições passivas na barragem do Paranoá. A camada mais superficial representa o solo inconsolidado, seguida por uma camada de argila compactada do aterro. Por fim, incluímos uma camada mais profunda de alta velocidade. A geometria e propriedades do modelo podem ser observados na Figura 11.

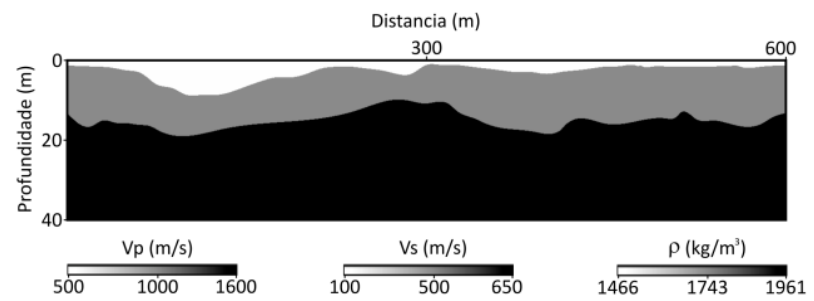

Figura 11 - Propriedades físicas do modelo geológico da barragem do Paranoá.

A crista da barragem é uma rodovia, logo a maior parte do ruído presente é gerado pelo tráfego de veículos. O estudo de Planès et al. (2017) foi realizado em um dique perto de uma rodovia, em que os autores analisaram o conteúdo espectral do ruído e concluíram que somente o tráfego contribuiu para o espectro, restrito à porção superficial. Por este motivo, alteramos o espalhamento das fontes ruidosas no modelo para avaliar se isso causa alguma diferença nas correlações. Realizamos uma aquisição com as fontes espalhadas por todo o modelo (Figura 12a) e outra em que concentramos as fontes nos 5 primeiros metros de profundidade (Figura 12b).

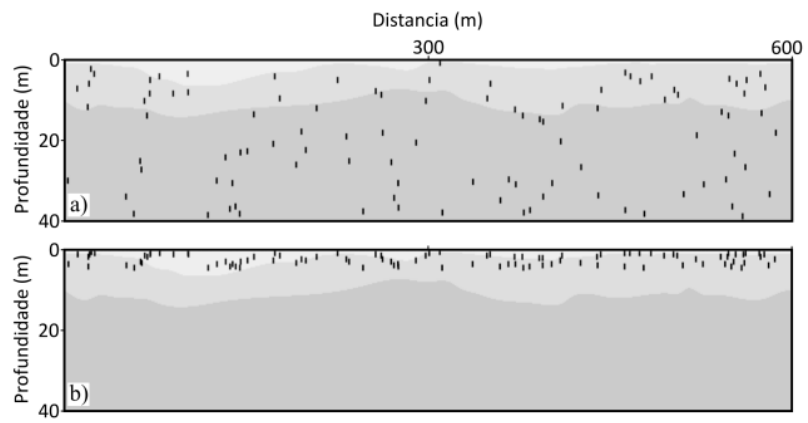

Figura 12 - Fontes ruidosas distribuídas de forma aleatória ao longo de (a) todo o modelo e (b) restritas aos 5 primeiros metros de profundidade.

O tempo de aquisição foi definido como 120 segundos e o espaçamento entre os receptores como 1 metro. A borda superior foi alterada para uma superfície livre. Assim, a energia é refletida ao chegar nos receptores, o que gera múltiplas nos registros. $O$ resultado da aquisição pode ser observado na Figura 13. As amplitudes da Figura 13a são mais fortes do que a Figura 13b. As regiões com maiores offsets não foram muito bem resolvidas. Isso indica novamente que é preciso cuidado na determinação do offset para garantir a recuperação de todos os alvos de interesse.

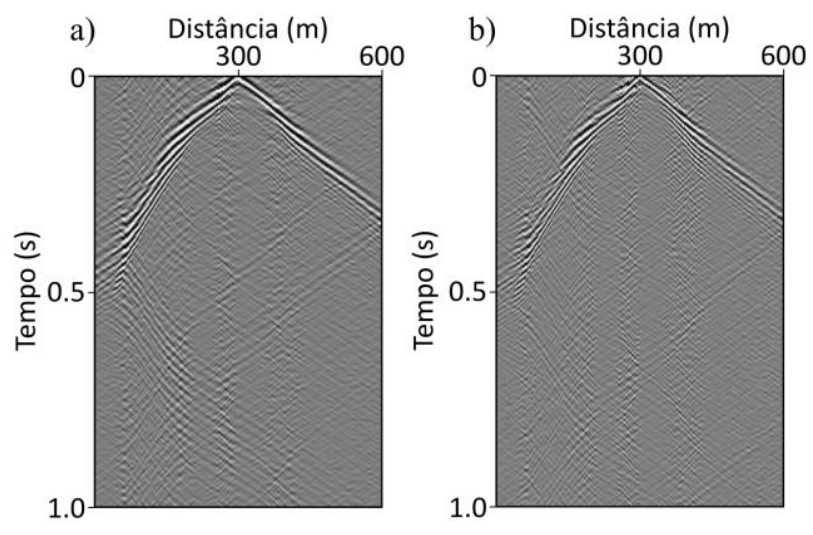

Figura 13 - Sismogramas recuperados para a barragem do Paranoá. (a) Situação em que as fontes estão presentes em todo o modelo; (b) Situação em que as fontes são concentradas nos primeiros 5 metros de profundidade.

Também simulamos um processo de saturação das duas primeiras camadas do modelo da barragem. As velocidades e os resultados das correlações são apresentados na Figura 14. Novamente, notamos alteração nas assíntotas das hipérboles, o que mostra que o método é sensível a variações de velocidades em modelos mais complexos. Além disso, também é possível perceber um aumento na quantidade do ruído ambiental. 


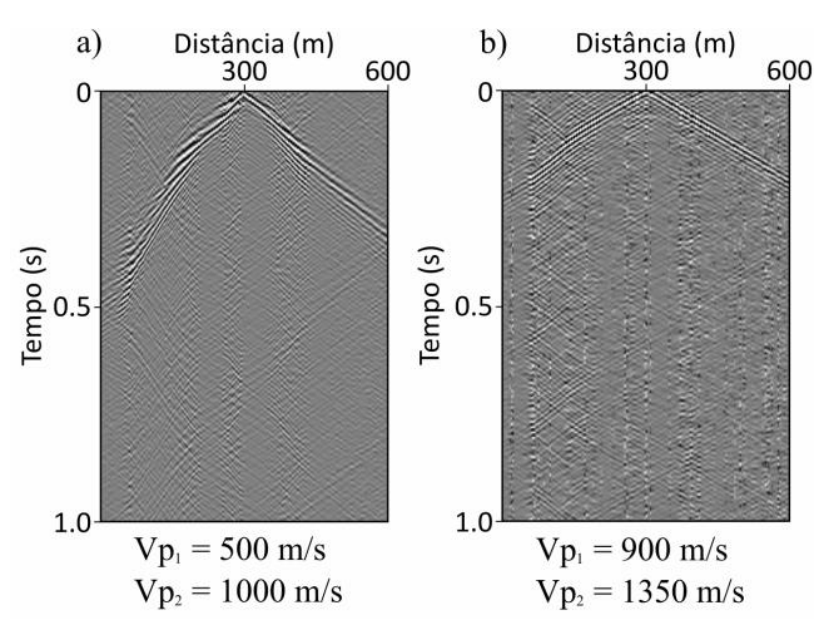

Figura 14 - Comparação entre os sismogramas recuperados na barragem. (a) Modelo inicial e (b) modelo saturado.

Não mostramos os resultados dos painéis de monitoramento para o caso da barragem pois nossa implementação limitada não geraria bons resultados no caso de um refletor irregular. A implementação já está em andamento, e publicaremos os resultados em breve.

Após a análise dos resultados obtidos nos modelos da barragem do Paranoá, percebemos que alguns pontos relevantes para a aplicação da interferometria sísmica no monitoramento de barragens não foram resolvidos. Não foi possível discutir a profundidade máxima que conseguimos monitorar com sísmica passiva. Isso depende da assinatura do ruído, como assinatura espectral e intensidade, o que sugere um estudo mais aprofundado sobre a natureza dos ruídos na barragem. Outra questão importante é a determinação da cobertura ideal da estrutura, que pode ser investigada variando o offset nos modelos sintéticos e avaliando a precisão do cálculo dos painéis de monitoramento para cada caso. Esses pontos serão objeto de estudo de novas pesquisas.

\section{Conclusões}

O levantamento sísmico com fontes ativas na barragem do Paranoá permitiu a criação de modelos sintéticos que se aproximam da estrutura esperada. Os modelos simples de duas camadas permitem 0 melhor entendimento do funcionamento da técnica e traz informações que podem ser aplicadas em campo. O método é sensível a variações de velocidades em modelos simples e no modelo criado para a barragem. Os painéis de monitoramento apresentam boas perspectivas, uma vez que detectaram aumento da Vp no modelo de duas camadas. O código ainda não está finalizado e requer uma série de melhorias, como a implementação de janelas de abertura, definição da abertura e traçador de raios. Assim, os painéis podem ser desenvolvidos para situações complexas com poucas alterações. A interferometria sísmica é um método viável de ser aplicado no monitoramento de barragens de terra de forma a complementar as informações sobre estrutura e variações de propriedades físicas. Estudos futuros irão focar na implementação dos recursos faltantes nos paineis de monitoramento, e na aplicação do método em dados de campo de sísmica passiva.

\section{Acknowledgments}

Agradeço ao doutorando Jahiro Calvet por todo o auxílio com o desenvolvimento deste trabalho.

\section{References}

ALBUQUERQUE, R., BRAGA, M.A, OLIVEIRA, L.A., OLIVEIRA DIAS, L.S., ALMEIDA, A.P., OLIVEIRA, A.H., BRANDÃO, S. 2019. Caracterização de barragens de rejeito utilizando geofísica rasa: aplicação na barragem b1 de Cajati, São Paulo. Anuário do Instituto de Geociências, 42, 567-579.

BERKHOUT, A.G. 2017. Utilization of multiple scattering: the next big step forward in seismic imaging. Geophysical Prospecting, 65, 106-145.

CAMPILLO, M., PAUL, A. 2003. Long-range correlations in the diffuse seismic coda. Science, 299, 547-549.

DE WIT, T., OLIVIER, G. 2018. Imaging and monitoring tailing dam walls with ambient seismic noise. $21^{\text {st }}$ International Seminar on Paste and Thickened Tailings. Australian Centre for Geomechanics, 455-464.

DRAGANOV, D., CAMPMAN, X., THORBECKE, J., VERDEL, A., WAPENAAR, K. 2009. Reflection images from ambient seismic noise. Geophysics. 74, A63-A67.

FLORES-BERRONES, R., RAMÍRES-REYNAGA, M., MACARI, E.J. 2011. Internal erosion and rehabilitation of an earth-rock dam. Journal of Geotechnical and Geoenvironmental Engineering. 137, 150-160.

KNIGHT, R., NOLEN-HOEKSEMA, R. 1990. A laboratory study of the dependence of elastic wave velocities on pore scale fluid distribution. Geophysical Research Letters. 17, 1529-1532.

MACIEL, S., BILOTI, R. 2020. A statistics-based descriptor for automatic classification of scatterers in seismic sections. Geophysics. 85, 083-096.

NEIDELL, N.S., TANER, M.T. 1971. Semblance and other coherency measures for multichannel data. Geophysics. 36, $482-497$.

PLANÈS, T., MOONEY, M., RITTGERS, J.B., PAREKH, M., BEHM, M., SNIEDER, R. 2016. Time-lapse monitoring of internal erosion in earthen dams and levees using ambient seismic noise. Géotechnique. 66, 301-312.

PLANÈS, T., RITTGER, J.B., MOONEY, M., KANNING, W., DRAGANOV, D. 2017. Monitoring the tidal response of a sea levee with ambient seismic noise. Journal of Applied Geophysics. 138, 255-263.

THORBECKE, J., DRAGANOV, D. 2011. Finite-difference modelling experiments for seismic interferometry. Geophysics. 76, H1-H18.

WAPENAAR, K., DRAGANOV, D., SNIEDER, R., CAMPMAN, X., VERDEL, A. 2010. Tutorial on seismic interferometry: Part 1 - basics principles and applications. Geophysics. 75, 75A195-75A209. 